\title{
Employment outcomes and plant closures in a post-industrial city: an analysis of the labour market status of MG Rover workers three years on.
}

\author{
Forthcoming: Urban Studies
}

\author{
David Bailey, Caroline Chapain and Alex de Ruyter ${ }^{1}$
}

\begin{abstract}
This paper examines how the loss of 6,300 jobs from the closure of MG Rover (MGR) in the city of Birmingham (UK) in April 2005 affected the employment trajectories of ex-workers, in the context of wider structural change and efforts at urban renewal. The paper presents an analysis of a longitudinal survey of 300 ex-MGR workers, and examines to what extent the state of local labour markets and workers' geographical mobility - as well as the effectiveness of the immediate policy response and longer term local economic strategies - may have helped balance the impacts of personal attributes associated with workers' employability and their reabsorption into the labour markets. We find that the relative buoyancy of the local economy, the success of longer-run efforts at diversification, and a strong policy response and retraining initiative helped many disadvantaged workers to find new jobs in the medium term. However, we also highlight the unequal employment outcomes and trajectories that many lesser-skilled workers faced. The paper explores the policy issues arising from such closures and their aftermath, such as the need to coordinate responses, to retain institutional capacity, to offer high quality training and education resources to workers, and where possible to slow down such closure processes to enable skills to be retained and reused within the local economy.
\end{abstract}

\section{Introduction: labour market restructuring and urban renewal}

Labour market restructuring has been an important feature of change in UK urban areas over the last 25 years. The processes of deregulation, privatisation, technological change and globalisation have combined to reshape the urban economic landscape (MacKinnon et al., 2008). Some industries have grown, whilst others have declined. In particular, there has been a dramatic process of deindustrialisation with UK employment in manufacturing decreasing from $7,053,000$ in 1979 to 2,730,000 in 2009 (Hudson, 2010). In turn, the debate on structural change has been intimately linked to the discussion on the emergence of the 'post-industrial city' (Gospodini, 2009), and the need to embrace urban revival (van Winden, 2008). In such a context, it is often argued that industrial cities need to reinvent themselves and provide an accommodating environment for growth sectors, so as to better cater for the (higher-value added) jobs of the future, in finance, information technologies, other high-tech services, or other "desirable" consumption sectors such as creative and cultural industries (see Mommaas, 2004; Gospodini, 2009).

${ }^{1}$ Coventry University Business School, Birmingham Business School and Canterbury Christ Church University, respectively. All authors contributed equally to this paper. We are grateful to the support of the Economic and Social Research Council under award number RES-000-222478. 
However, the reality of employment change and urban regeneration in the UK has painted a much more mixed picture. Jobs growth between high-skilled and low-skilled sectors continues to display severe regional and intra-urban disparities, with high-skill/high-wage jobs being skewed towards London and the South-East, and far smaller islands of prosperity in urban centres elsewhere (Glasmeier et al., 2008). Hence, whilst total employment in the UK has grown (until the recession of 2007-9 at least), many newly-created positions have been in sub-standard lowpaid, low-skilled occupations (Nolan, 2004). Many lesser-skilled workers leaving declining industries, largely concentrated in outer-suburban areas, have therefore been at risk of underemployment, long-term unemployment, or leaving the workforce entirely (Dorling, 2009). Current policies and programmes may not have adequately addressed the difficulties confronting such groups and associated local communities (Nolan, 2004) - particularly when considering the uneven socio-spatial impact of unemployment (and recent financial crisis) in the UK to date, which has been disproportionately concentrated in the urban centres of the Midlands and North of England, Wales and Scotland (Clayton, 2009).

In this context, the closure of the MG Rover (MGR) plant at Longbridge in the West Midlands in April 2005 was one of the most significant in the UK for twenty-five years; with the loss of some 6,300 jobs. The closure of the plant took place in a context of a continuous and rapid local and regional economic transformation from manufacturing dependence towards the 'new economy' supported by local and regional clustering and up-skilling economic strategies. As such, the closure represents an interesting case study of labour market adjustment (Bailey et al, 2008), and how such issues need to be situated in their specific local and regional socio-economic and policy environments. This is particularly relevant as MGR workers predominantly lived in the periphery of Birmingham and neighbouring outer suburban localities (Chapain and Murie, 2008) displaying very different local labour markets. Examining the labour market experience of MGR workers in these contexts will help us assess whether ex-Prime Minister Blair's view that exMGR workers would be able to find "full and fulfilling jobs" was indeed realised. In doing so, we look at the nature of jobs entered into (income levels, employment status etc.) over the medium term. Indeed, most research looking at the impacts of plant closures on people and place tend to examine these impacts at one point in time, usually within the first or two years after the closure. Our research offers a longitudinal perspective allowing us to follow the employment trajectories of the workers being made redundant from three months to three years after the closure.

The paper is structured as follows. The following section discusses the socio-spatial aspects of economic restructuring and labour market change, before introducing the particular features of the MG Rover closure in Birmingham and the West Midlands. After outlining data and methods used (notably the use of a longitudinal survey and follow-up interviews), findings are presented in terms of: workers' characteristics, employment outcomes and trajectories; the impact of local labour markets and workers' geographical mobility; and the effectiveness of specific policy and wider local and regional strategies. After discussion and consideration of policy implications, concluding thoughts round off the paper.

\section{Exploring the socio-spatial aspects of plant closure and labour market adjustment}

Job losses arising from plant closure are examples of labour market adjustment due to economic restructuring; and have been studied by a number of researchers (Pinch and Mason, 1991; Hinde, 1994; Tomaney et al., 1999; Kirkham and Watts, 1998; Henderson and Shutt, 2004; Pike, 2005). Such studies have followed two major approaches. The first group of studies (particularly on multi-plant closures) has tended to examine the nature of plant closures themselves, whilst the second group has focused on the aftermath of closures and their impact on the workers being made redundant and the local economy. 
There are a number of ways in which one might conceptualise the impact of redundancy on individuals and communities. The first view that the costs of adjustment are short-term and that displaced workers would be able to find employment in more productive firms/industries (O'Farrell and Crouchley, 1983) and/or migrate to where job growth is occurring (Armstrong and Taylor, 1993). Here, policy initiatives would consist merely of re-training individuals to meet the needs of emerging industries and encouraging labour mobility. However, other authors argue that such an abstract view of labour market adjustment could downplay personal and community factors pertaining to job search (Hinde, 1994). Older workers, in particular, could place a higher premium on staying within their community than on relocation (ibid). Social networks can also be seen to link household and employment opportunities and hence define social identities which in turn can constitute a key determinant of which workers get jobs (Harris, 1987).

The nature and duration of impacts are thus mitigated by various factors. Personal attributes such as gender, age, personal and marital status and levels of skills and education play an important role (Wooden, 1988). Previous research showed that the likelihood and speed of finding another job decline with age and increase with levels of education and skills (Wooden, 1988; Tomaney et al., 1999). Women also have a greater chance of withdrawing from the labour market than men in the case of lay-offs, while research also suggests that married men spent less time unemployed compared with single men (Wooden, 1988). Changes in commuting and migration are also potential responses to job loss (Hinde, 1994; Bailey and Turok, 2000). However, there is still debate over the importance of these responses for workers with different occupations and levels of income (Bailey and Turok, 2000; Dawley, 2007). There are a number of issues associated with coping strategies adopted by households and their response will depend upon their resources, needs and choices. How, for example, are decisions about relocation affected by housing tenure, and/or spouses working locally and/or potential disruption in children' education?

These issues connect with a consideration of neighbourhood effects and the impacts of the closure on the local economy. If the workforce was concentrated in occupational communities very close to the workplace then significant local impacts may be likely. However, where the workforce is more dispersed then the impact might not be spatially concentrated at all, or alternatively, the places where impact is felt most severely might not be adjacent to the workplace at all. As such, there are important issues regarding the absorptive capacity of the local (and regional) labour market when a sudden influx of relatively skilled workers occurs following plant closure (Dawley, 2007). In particular, research has shown that redundant workers find work more quickly if the closure happens in a buoyant local labour market (Pinch and Mason, 1991).

As Pike (2005) notes, the roles of social agency and particular socio-institutional, temporal and spatial contexts are often underplayed when analysing the impact of plant closure. Plant closure can be seen not merely as a case of shut-down due to economic imperatives operating at a higher level of abstraction, but rather as a contingent, path-dependent process (Tomaney et al., 1999). Here, the role of institutions and the interaction between business strategy and legal regulation is pivotal (ibid.). In this context, the role of the state becomes crucial in setting the parameters within which a process of adjustment will take place; both in terms of maintaining a sound macroeconomic climate and alleviating the impact of external shocks, and also in terms of what opportunities or assistance can be provided to individual firms and workers at the local or regional level (or the "activities of institutions in resettling redundant workforces" - see Dawley, 2007: 1404). 
In this context, Shuttleworth et al. (2005) argue that three important dimensions need to be taken into account when examining the employment outcomes and trajectories of workers being made redundant after a plant closure:

1. The personal attributes associated with workers' employability and re-absorption in the labour market;

2. The local demand and geographical mobility shaping their transition back to employment;

3. The effectiveness of the policy interventions, their uptake and how were they perceived by the workers.

We argue that the wider local and regional policy environment and long term economic strategies put in place need to be taken in to account as well as they will have strong linkages with dimensions two and three. In what follows we highlight the demise of the MGR plant at Longbridge and discuss the local and regional economic and policy environments (dimensions 2 and 3) in which this demise took place. We then analyse and review to which extent these two dimensions have balanced the first dimension highlighted by Shuttleworth et al. (2005) i.e. the personal attributes associated with workers' employability. In so doing, we also begin to assess the relative effectiveness and usefulness of the specific policy measures used in the aftermath of the MGR crisis. In doing so, we will try to distinguish between the impacts of the specific policy response associated to the closure with the wider policy framework put in place to foster urban renewal and regeneration in the city and the region. We consider that successful policy adjustments extend beyond merely providing "jobs" or "job opportunities" for displaced workers. They extend to the quality of employment and lasting career opportunities.

\section{The MG Rover closure in Birmingham and the West Midlands}

Up to the 1960s, Birmingham and the West Midlands were characterised by rapid economic growth and prosperity, based on strengths in metal goods, motor-vehicle and electrical equipment manufacturing. However, the city and the region were strongly hit by the recessions and manufacturing crisis of the 1970s and the 1980s leading to significant levels of unemployment (Brown et al. 2007) and ongoing deindustrialisation. At the turn of this century, the newly created regional development agency set out its economic development strategy based initially on priority business sectors and later on ten clusters in line with national policy (Bailey and MacNeill, 2008). Additional regional initiatives included the development of three technology corridors, one of which, the Central Technology Belt (CTB) included the Longbridge area. These initiatives included a mix of training, business support, and infrastructure provision and were developed in partnership with other local and regional public organisations and the private sector (ibid). The local and regional economy underwent importance changes with regard to its economic make up from 1995 to 2008 with the city moving away from its concentration on manufacturing activities and increasing its service sector activities (Table 1). This diversification, along with strong national economic growth, had positive impacts on the local and regional economy, with the period 1999-2005 marked by decreasing levels of unemployment with the claimant count in the city falling from $9.4 \%$ in 1999 to $7.6 \%$ in 2004, and in the region from 5\% to $3.7 \%$ respectively (Birmingham City Council, 2009). Nevertheless, these levels remained higher than national averages. 
Table 1: Employment by economic sectors (1995-2008)

\begin{tabular}{|l|r|r|r|r|r|r|r|r|r|}
\cline { 2 - 10 } \multicolumn{1}{c|}{} & \multicolumn{3}{c|}{ Birmingham } & \multicolumn{3}{c|}{ West Midlands } & \multicolumn{3}{c|}{ Great Britain } \\
\cline { 2 - 11 } & $\mathbf{1 9 9 5}$ & $\mathbf{2 0 0 5}$ & $\mathbf{2 0 0 8}$ & $\mathbf{1 9 9 5}$ & $\mathbf{2 0 0 5}$ & $\mathbf{2 0 0 8}$ & $\mathbf{1 9 9 5}$ & $\mathbf{2 0 0 5}$ & $\mathbf{2 0 0 8}$ \\
\hline Manufacturing & 23.0 & 12.5 & 10.0 & 26.1 & 15.2 & 13.8 & 17.6 & 11.1 & 10.2 \\
\hline Construction & 4.0 & 3.8 & 3.4 & 3.8 & 4.5 & 4.9 & 4.0 & 4.6 & 4.8 \\
\hline $\begin{array}{l}\text { Distribution, } \\
\text { hotel and } \\
\text { restaurant }\end{array}$ & 19.7 & 21.0 & 21.7 & 22.8 & 24.2 & 23.6 & 23.6 & 24.1 & 23.4 \\
\hline $\begin{array}{l}\text { Transport and } \\
\text { communications }\end{array}$ & 6.0 & 5.1 & 4.8 & 48.0 & 5.6 & 5.8 & 5.9 & 6.0 & 5.8 \\
\hline $\begin{array}{l}\text { Banking, finance } \\
\text { and insurance }\end{array}$ & 18.1 & 21.3 & 23.0 & 14.2 & 17.5 & 18.6 & 17.8 & 20.7 & 22.0 \\
\hline $\begin{array}{l}\text { Public } \\
\text { administration, } \\
\text { education and } \\
\text { health }\end{array}$ & & & & & & & & & \\
\hline
\end{tabular}

Source: Annual Business Inquiry

It is in this economic and policy context that the closure of MG Rover at Longbridge took place in 2005. It is important to note that the plant was first threatened with closure in 2000 , resulting in the implementation of a specific programme to diversify the regional economy into nonautomotive sectors. The Task Force model developed at that time (Bailey, 2003) also served as a basis to deal with the final closure of the plant in 2005. The second Rover Task Force created in 2005 put together a package of $£ 176$ million to support actions directed at MG Rover suppliers, vehicle retailers and workers and the local community around Longbridge. Actions to support the workers included facilitating access to Job Centre support and statutory redundancy payment and compensation ( $\$ 40$ million) and dedicated training programmes ( 50 million) (Bailey and MacNeill, 2008).

In summary, the closure of MG Rover took place in a period of significant economic growth and economic diversification for Birmingham and the West Midlands. In addition to existing local and regional economic strategies supporting the growth of new economic sectors and up-skilling of the local and regional workforce, the closure also generated an important dedicated policy response.

\section{Methods and data}

The data used in this article is derived from a three-wave longitudinal survey of ex-MGR workers, building on the findings of Bailey et al (2008). Letters were sent to all ex-MGR workers inviting them to participate in the study via a telephone interview consisting of a series of structured questions, enabling ready comparison of results. This was conducted in strict accordance with the ethical principles of fully-informed voluntary participation, anonymity and confidentiality. The third wave of this survey (which is the focus of this article) was carried out in April 2008; three years after the closure. It was designed to follow on from the previous two surveys of ex-MGR workers carried out by The Work Foundation in conjunction with BBC Radio 4's Life after Longbridge series and thereby provide a unique three-wave longitudinal survey.

Ex-MGR workers were first interviewed in July 2005 (Wave One, three months after the closure), again in December 2005 (Wave Two, eight months after the closure and finally in April 2008 (Wave Three, three years after the closure). In the first wave, 273 interviews were conducted with ex-MGR workers. At the second wave, 232 interviews $(86 \%$ of the original sample) were conducted, and in the third wave 204 interviews were conducted, with 176 ex- 
workers across all three waves and 19 new volunteers. The demographic profiles of the samples were representative of the MGR workforce. Similar to the MGR workforce, the thirdwave sample was $93 \%$ male, and the majority (over $70 \%$ ) of workers were aged between 40 and 54 (with an average age of 48 years) and had worked on average for 21 years at MGR. The average yearly salary of the ex-workers interviewed at MGR was $£ 27,624$ or a weekly salary of $£ 514$, as compared with $£ 404$ for a full time worker (£444 for a man) in the West Midlands in 2005. Some $98 \%$ of the sample had worked full-time at MGR, with around a third of workers then being process, plant and machine operatives; just under $20 \%$ were in skilled trades, $8 \%$ in administrative and secretarial positions, $9 \%$ in associate professional and technical jobs, $12 \%$ were professional and $18 \%$ in manager roles. Only $11 \%$ had no qualification which was lower than the regional average. Almost $80 \%$ of the respondents were married (compared with $42 \%$ in the West Midlands), with almost no change from the Wave One survey. Some $93 \%$ were homeowners (with 55\% still paying a mortgage) in 2008; which was higher than the regional average $(70 \%)$. Overall, this enabled a high degree of generalisation of the findings to the whole ex-MGR workforce.

The survey data was supplemented with qualitative interview data obtained from ex-workers (over 20 in total). These interviews were conducted between July 2008 and April 2009 and consisted of semi-structured interviews, during which issues pertaining to labour market adjustment were further explored.

\section{Findings}

This section presents our findings with regards to the employment outcomes and trajectories of the MG rover workers against the three main dimensions discussed above, notably: 1 . workers personal characteristics; 2. the state of the local and regional labour market plus workers' mobility; and 3 . the effectiveness of policy interventions.

Workers' Characteristics, employment outcomes and trajectories

\section{Employment outcomes in 2008}

Prima facie, it could be argued that ex-MGR workers had undergone successful labour market adjustment. Evident from our findings was that approximately $90 \%$ of ex-MGR workers in our sample were in some form of employment in April 2008, with nearly three-quarters employed full-time, around $11 \%$ self-employed and just under $5 \%$ employed part-time. In terms of contractual arrangements, some $86 \%$ of ex-MGR workers employed said that they were in a 'permanent' job, with the remainder (14\%) employed on a casual basis, or on fixed-term contracts, or via agency work. This in turn could suggest that ex-MGR workers "leapt to the front of the jobs queue" in that as relatively skilled, experienced workers, they may have been seen as more desirable to employers than the existing unemployed. However, another $5 \%$ were unemployed and looking for work and $2 \%$ were unemployed and not looking for work. These findings are illustrated in Table 2. Overall the activity rate in our sample was over $95 \%$, and actually above the average for the West Midlands of $83 \%$ for the same period.

In considering worker characteristics, overall, workers in full time employment were more likely to be male and younger, having worked a slightly shorter period of time at MGR. On average, workers in self-employment at Wave Three were older, more qualified, had been in managerial or professional at MGR, and owned their own house. Common occupations taken up by selfemployed workers included work related to the car industry (such as independent automotive engineers and consultants) but also quite different areas of work such as plumbers, carpenters, gardeners, and driving instructors. The frequency of the first two groups (independent auto engineers and consultants) amongst self-employed workers may help explain why it has been 
ex-workers with higher occupational profiles who were more likely to have gone into selfemployment. Roughly $70 \%$ of respondents who were self-employed in Wave Three were in managerial or professional occupations at MGR. In contrast, workers employed part-time at Wave Three were more likely to be female, had higher qualifications, had worked a long period of time at MGR and by 2008-9 were working in services. Respondents that were still unemployed and looking for work at Wave Three were more likely to be older, had lower levels of qualification and did not own their house. Finally, respondents that were inactive at Wave Three were more likely to be close to retirement age, to be female, to have lower levels of qualification and to own their house.

Table 2: Main employment status at Wave Three (April 2008)

\begin{tabular}{|l|r|r|r|}
\hline & Wave One & Wave Two & Wave Three \\
\hline Total number of respondents & 185 & 176 & 204 \\
\hline Employment status (\%) & & & \\
\hline Self-employed & 2.2 & 4.5 & 10.8 \\
\hline Employed full-time & 22.7 & 52.3 & 73.5 \\
\hline Employed part-time & 2.2 & 3.4 & 4.4 \\
\hline Still employed at MGR & 4.3 & 2.3 & - \\
\hline In full-time education/training & 4.9 & 4.5 & 1.0 \\
\hline In part-time education/training & 2.2 & 0.6 & 1.5 \\
\hline Unemployed, looking for work & 58.4 & 28.4 & 4.9 \\
\hline Unemployed, not looking for work & 1.6 & 0.6 & 2.0 \\
\hline Caring for children or relatives & - & - & 0.5 \\
\hline Retired & - & 0.6 & 0.5 \\
\hline Other or on incapacity/disability benefit & 1.6 & 2.8 & 1.0 \\
\hline
\end{tabular}

Source: Bailey et al (2008).

Note: In order to allow for a longitudinal analysis, this table only includes respondents from Wave One and Two that were part of the Wave Three survey. This explains why the number of respondents for Waves One and Two are lower than the number of people interviewed for each Wave respectively.

These brief demographic profiles by employment status suggested that some ex-MGR workers could have encountered difficulties in finding work according to their specific characteristics. These problems were confirmed by respondents' answers. Opportunities for re-employment were tempered by the problems that ex-workers felt they had to face, with nearly two-thirds of those employed and over $80 \%$ of those unemployed at April 2008 reporting such problems. Key problems cited by ex-workers are detailed in Table 3. These included too many people applying for the same job, age, a negative reputation of MGR workers, a lack of skills and experience, as well as the opposite problem, that of being over-qualified for the jobs available. This could explain why around $70 \%$ of workers found their job through personal connections and initiative, including personal contacts (including family and colleagues) (29\%), searching via newspapers and the internet (27\%), approaching firms directly (10\%), and starting their own firms (6\%). 
Table 3: Problems in finding employment

\begin{tabular}{|l|r|r|}
\hline & $\begin{array}{r}\text { Employed at } \\
\text { Wave Three }\end{array}$ & $\begin{array}{r}\text { Unemployed at } \\
\text { Wave Three }\end{array}$ \\
\hline $\begin{array}{l}\text { Proportion of respondents who faced problems trying to } \\
\text { find employment after MGR (\%) }\end{array}$ & 64.2 & 83.3 \\
\hline & & \\
\hline Problems faced (\%) & 51.9 & \\
\hline Age & 35.6 & 46.7 \\
\hline Lack of skills or experience & 27.9 & 40.0 \\
\hline Over-qualified & 59.6 & 20.0 \\
\hline Too many people applying for same job & 36.5 & 66.7 \\
\hline The negative reputation of MGR workers & 3.8 & 26.7 \\
\hline Lack of support from Job Centre & 1.9 & n/a \\
\hline No specific or official qualification & 3.8 & n/a \\
\hline Health or disability problem & 2.9 & n/a \\
\hline No local jobs & 1.9 & n/a \\
\hline Too few jobs in my specific qualification & 1.9 & n/a \\
\hline Other: wanting a permanent job & n/a \\
\hline
\end{tabular}

Source: Bailey et al (2008).

\section{Workers' trajectories}

Given such challenges, it is also pertinent to examine the number of jobs that ex-workers have had since the closure. Workers had often had more than one job since working at MGR. Approximately half of those employed full-time at Wave Three reported having had more than one job since leaving MGR, as had those in full-time education and training. All of the workers in part-time employment and in part-time education and training reported that they had worked in more than one job since MGR. In addition, approximately half of those unemployed and looking for work, and three-quarters of those unemployed and not looking for work reported having had more than one job since leaving MGR. The impact of the recent recession (particularly on the manufacturing sector and auto industry in particular) was also felt, with some respondents who had obtained permanent employment by April 2008 reporting subsequent job loss in the downturn, as explained by one ex-worker who had obtained a job elsewhere as a tooling manager and was hiring other ex-workers:

"When I started with [Tool Co] they got me to employ more people. I took on 10 ex-MGR workers six months after Rover went bust - but now, of those ten, I only have three left who are permanent full-time. Two others are working on-and-off as casuals, and the other five have all gone.

I was going to 8 or 9 companies. Now three of them are out of business and of those that are left, most are on three-day weeks and have lost 40 to $50 \%$ of their workforce. It's carnage in the car industry at the moment"' (Worker 8, April 2009). 
In the UK, all employees with more than 12 months' tenure in their job can file for unfair dismissal should they be arbitrarily dismissed (Waring et al., 2006). However, from our sample we can ascertain that only a quarter of respondents had the same job in April 2008 as in November 2005, six months after the closure; suggesting that for a significant proportion of the sample, lack of automatic entitlement to claim unfair dismissal could be a problem. Thus, whilst $75 \%$ of our sample had entered full-time employment by April 2008, the external labour market context remained fragile for many.

In fact the trajectory for adjustment differed in terms of demographic profiles. Evident was the fact that the time taken to re-enter the labour market appeared to be inversely related to age and the length of work at MGR as well as levels of qualifications. Younger, more skilled workers and those who were prepared to commute further generally found work quicker, whilst for older workers and lower-skilled workers, successful adjustment was more problematic. Other individual factors that could affect the trajectory of adjustment included the level of occupation at MGR and income. These differences are explored in more detail next.

Incomes: a story of polarisation and overall decline

The previous study (Bailey et al, 2008) examined the findings from Waves One and Two. This research revealed that MGR workers' salaries were on average lower than when at MGR. Three years on, a key question was whether workers' salaries recovered to their original - or even a higher - rate than at MGR. Using median estimates, workers' unadjusted annual salaries, adjusted for inflation, at the time of the Wave Three interview, were significantly lower than their final MGR salaries with a median salary difference of $-£ 5,640$ for those employed at Wave Three. This discrepancy represents a significant decline in annual wages. As one worker commented:

"since I left MGR, we've been living on savings; that won't last me until I die. I won't be able to go on holidays or anything like that..." (Worker 1, October 2008)

In one sense, this was perhaps to be expected: MGR provided relatively well paid (unionised) work compared to industry averages. For many workers, changing jobs also meant a loss in earnings not only from changing skills, but also the benefit in pay from length of service. However, critically our findings also indicate a greater dispersion of earnings and yet again a differential story, with an overall decline in the median concealing a marked polarisation; with a third of respondents reporting an increase in salary, and two-thirds a decrease in salary. By occupational group, managers were in 2008 earning just about the same as they did at MGR, while most other workers were earning less - elementary level workers having seen the greatest drop. Respondents also demonstrated a far higher degree of occupational earnings dispersion than the UK average. This can be seen in Table 4, where it is also apparent that those in managerial positions at Wave Three have done the most well in terms of earnings compared to the UK average. 
Table 4: Income by Occupation, April 2008

\begin{tabular}{|l|l|l|}
\hline & Wave Three & UK average \\
\hline Managers/senior officials & 42,000 & 35,422 \\
\hline Professionals & 25,000 & 34,260 \\
\hline Assoc. professional and technical & 22,400 & 27,286 \\
\hline Administrative and secretarial & 21,500 & 18,157 \\
\hline Skilled trades & 24,000 & 22,464 \\
\hline Personal services & 14,200 & 15,566 \\
\hline Process, plant and machine operatives & 16,720 & 20,738 \\
\hline Elementary & 14,560 & 16,393 \\
\hline
\end{tabular}

Source: Bailey et al (2008)

The overall comparison of income levels highlighted the relative drop in salaries that nearly all MGR workers witnessed after closure. However, occupation and industry were not the only factors to dictate the salary levels of workers beyond the closure. We also observed salary differences amongst workers who were re-employed shortly after the closure relative to those for whom re-employment took longer. Those who had found employment by eight months following the closure reported higher salaries three years on compared to those who were still unemployed eight months after the closure. Those amongst the last to find re-employment (i.e., by the time of the Wave Three interview) reported a loss in salary relative to their MGR salary, and reported lower salaries compared to those who found re-employment sooner. Finally, it was worth noting that for most ex-MGR workers their main source of personal income was salary (66\%). However, over $6 \%$ reported a pension as having been a main source of income at Wave Three.

The impact of local labour markets, and workers' geographical mobility

Authors (2008b) analysed the extent of the spatial impact of the closure of MGR, by using a payroll dataset of employees at MGR at two points in time (1998 and 2005). Both datasets provided postcodes for the home addresses of most MGR workers at that time, and they mapped this data in detail. The 1998 dataset also comprised information on age, type of occupation for each employee (executive, hourly workers, managerial staff, general staff and trainees). There were 13,127 people working at MGR in 1998, with the bulk of employees living in a triangle stretching across the south of Birmingham, extending along the A38 to Bromsgrove, Redditch and Wychavon in the south and to Dudley and Sandwell in the west. Around $20 \%$ of MGR employees lived in the Birmingham Northfield constituency (the wards of Longbridge, Northfield, Kings Norton and Weoley) in 1998, with the largest number in Longbridge (9\%) and Northfield (6\%). There were also important pockets of employees in other parts of Birmingham and together this comprised $45 \%$ of where the workforce lived.

The total number employed at MGR had decreased to 5,858 by 2005 . However, there was relatively little change in the geographical distribution of MGR employees across south Birmingham by the time of the closure in 2005. There are two immediate implications from this. Firstly, while there was a 'local' concentration effect there was also a widely dispersed workforce and the spatial impact was therefore sub-regional rather than local. Secondly by the time of the closure in 2005, all of the areas affected by that closure had already been affected 
by earlier job losses. The MGR closure could thus be seen as the final shock - following on from a period of long decline which had already affected the labour market and would affect the capacity to adjust to the shock. Indeed, by 2005, the firm was already effectively 'hollowed out'. The spatial impact can be ascertained by considering data available on MGR employees, disaggregated by the type of job for 1998 . Hourly paid workers $(74 \%)$, general staff $(14.8 \%)$ and management staff $(8.8 \%)$ formed the three main categories of the MGR workforce. The majority of hourly paid workers lived in Birmingham (50\%), Dudley (15\%) and Sandwell (10\%). In contrast, executive employees were more dispersed, with only $20 \%$ of them living in Birmingham, Dudley and Bromsgrove. More than half of management staff lived outside these three districts. The pattern for general staff lay between these two extremes and involved a more even distribution regionally: $40 \%$ of them lived in Birmingham, 17\% in Bromsgrove, $9 \%$ in Dudley and $30 \%$ were dispersed across the rest of the West Midlands.

Overall, this suggests that the impact of the plant closure on local labour markets is likely to have been uneven spatially and profession-related (Chapain and Murie, 2008). It also suggests that some of the redundant workers were competing for similar jobs in areas of Birmingham and the West Midlands. Their chances to re-enter employment were thus dependent on the state of the local labour market as well their propensity to travel to access job opportunities in the regional market. As discussed previously, the city and the region had enjoyed relative economic prosperity in the first half of the 2000s and a decline in unemployment rates. However, this situation changed in 2004-2005 with unemployment rates rising again in Birmingham and the West Midlands. This rise was not uniform across the region with neighbouring local authorities such as Bromsgrove, Dudley and Sandwell experiencing a decline in their unemployment rates from 2004-05 to 2005-06 (see Table 5). As such, the local and regional labour market contexts varied by locality for workers with a given skill set - with some areas less enabling than others. Most local labour markets, however, worsened over time with the recent economic downturn, which affected the West Midlands more severely than any other UK region. Indeed, the regional unemployment rate increased from approx. 6.5\% in August 2008 to over $10 \%$ by July 2009, whilst Fothergill (2009) demonstrated that for many old industrial areas such as Birmingham, Wolverhampton and Sandwell, the real joblessness rate was by 2009 well above $15 \%$ (joblessness being defined as the officially unemployed plus hidden unemployed such as discouraged jobseekers).

The fact that the great majority of workers were in full-time employment at Wave Three seems to indicate that despite the rise in unemployment levels after 2005, the regional labour market was able to accommodate these workers over the medium term. However, findings from our survey suggest that some had to increase their commuting distance (40\%). This was particularly the case in workers residing in Birmingham (49\%) and Bromsgrove (46\%). In the latter case, some $59 \%$ of employed workers at Wave Three living in Bromsgrove had difficulty finding employment due to the fact that there were too many people applying for the same job (versus $38 \%$ on average for all employed workers at Wave Three). 
Table 5: Unemployment rates (\% working age population, Local Authority) April 2004 to March 2010

\begin{tabular}{|c|c|c|c|c|c|c|}
\hline Area & $\begin{array}{l}\text { Apr 2004- } \\
\text { Mar 2005 }\end{array}$ & $\begin{array}{l}\text { Apr 2005- } \\
\text { Mar 2006 }\end{array}$ & $\begin{array}{l}\text { Apr 2006- } \\
\text { Mar } 2007\end{array}$ & $\begin{array}{l}\text { Apr 2007- } \\
\text { Mar 2008 }\end{array}$ & $\begin{array}{l}\text { Apr 2008- } \\
\text { Mar 2009 }\end{array}$ & $\begin{array}{l}\text { Apr 2009- } \\
\text { Mar } 2010\end{array}$ \\
\hline & percent & percent & percent & percent & percent & percent \\
\hline Northfield ${ }^{* *}$ & 4.5 & 8.1 & 5.7 & 8.2 & 12.2 & 21.8 \\
\hline Birmingham & 8.8 & 9.5 & 9.5 & 9.6 & 11.5 & 13.7 \\
\hline Bromsgrove & 3.8 & 2.7 & $!$ & 6.2 & 3.9 & 4.3 \\
\hline Dudley & 6 & 3.1 & 5 & 5.4 & 8.4 & 10 \\
\hline Sandwell & 9.8 & 6.8 & 6.5 & 9.3 & 14.6 & 16.3 \\
\hline Walsall & 5.9 & 7.5 & 7.7 & 8.4 & 10.1 & 13.1 \\
\hline Wolverhampton & 5.6 & 6.5 & 7.8 & 9.8 & 10.3 & 14.4 \\
\hline West Midlands & 5.2 & 5.3 & 5.6 & 6.4 & 7.6 & 9.5 \\
\hline Great Britain & 4.8 & 5.1 & 5.4 & 5.3 & 6.3 & 8 \\
\hline
\end{tabular}

Source: Annual Population Survey

Notes: ! Estimate not available. ${ }^{* *}$ Estimates have a high confidence interval and are only provided to give a sense of the trend for Northfield.

\section{Effectiveness of specific policy interventions and wider local and regional economic strategies}

As noted, a range of policy interventions were put in place to help workers find new jobs. One of the key policy interventions was to offer training opportunities to workers to help them re-skill. The next section discusses the effectiveness of this intervention.

\section{Training: a relative success story}

Overall, training opportunities seem to have played an important role, especially for the workers who had difficulty finding a job in the manufacturing sector and who had to consider other job opportunities. At Wave One, findings from the survey indicate that around a quarter of the sample were not even aware that MGR workers were entitled to re-skilling in a manufacturing skill. Consequently, only $29 \%$ of the sample had actually taken advantage of the re-skilling opportunity. In addition, fewer than half of the workers were aware of the free training support available for wives and partners of MGR workers, resulting in just 5 out of the 273 having a partner enrolled in the training. At Wave Two, this picture was very similar, with not many more workers and their partners taking advantage of the services available to them. From the point of view of both workers and service-providers, this was clearly less than ideal and would appear to reflect a lack of effective communication as to what support was available. By Wave Three, the situation had improved dramatically, with $60 \%$ of respondents indicating that they had undertaken some form of training (including on job training).

A positive finding at Wave Three was that a majority of workers retrained to increase their opportunities or to change career or vocation. In particular, 35\% decided to retrain to increase their opportunities, $24 \%$ to change career, and $13 \%$ as a requirement of their new job. Interestingly, only $8 \%$ took up training as an alternative to unemployment, and $7 \%$ because they were simply unable to find work with their qualifications. Of those workers who had undertaken training, approximately $50 \%$ had trained towards a recognised academic qualification (mostly vocational in nature). The very fact that ex-workers pursued specific forms of academic and 
vocational training in a range of demanded skills such as information technology could help to explain some key findings of our study; notably the very positive uptake of training opportunities, in contrast to much other research on other plant closures (e.g., Shuttleworth et al., 2005, where a low take-up rate was reported). Finally, it is worth noting that those who were employed earlier (i.e., at Wave One) were less likely to receive training, whereas those who were not employed until later waves (Two and Three) were more likely to take up training, with the figure for the third trajectory (i.e., those unemployed at Waves One and Two but employed at Wave Three) most noticeable in that almost $80 \%$ of this trajectory had received training. Finally, two-thirds of those who received training reported that they found it helpful.

\section{Work: a shift into services}

Finally, we consider the local and regional strategy to move Birmingham and the West Midlands economy away from traditional manufacturing towards new sectors of the economy, and whether this played a role in the type of jobs that workers found.

An examination of the industries in which ex-MGR workers found employment three years on revealed a shift away from employment in manufacturing towards employment in service industries, mirroring the employment structure found in the local and regional economy. However, the proportion of our sample employed in manufacturing was still around double that of the regional average. This was particularly the case of workers who had already found another job at Wave One. In addition, greater proportion of workers found a new job in related sectors such as transport and communication.

Hence, major shifts also took place in occupational patterns from MGR, including (as expected) a shift away from employment as plant and machine operatives (from around a third of workers at MGR to around $20 \%$ of ex-workers at Wave Three), as well as a fall in the proportion classed as managers (from 18\% to 12\%) and professional (from 12\% to $3 \%$ ). At the same time there was an increase in employment at associate professional and technician status (from $9 \%$ to $15 \%$ ), in personal services (from zero to $9 \%$ ) and in elementary skills (from $2 \%$ to $12 \%$ ). This occupational shift was also reflected in the type of skills that workers reported using in their current roles; more than $60 \%$ of all those employed at Wave Three said that in their new jobs they were using different skills to those they used at MGR.

As such, the diversification of the economy away from traditional manufacturing supported by local and regional strategies seems to have enabled most workers to find another job. Nevertheless, this transition was not smooth for all workers and as noted in some cases resulted in lower occupational levels and in many cases in significantly lower salaries.

\section{Summary}

The findings above paint a mixed picture for ex-MGR workers. Clearly evident was that most had made a successful transition into another job by Wave Three, with $90 \%$ having obtained some form of full-time employment three years after the closure (including self-employment). In a similar manner, success was also apparent in terms of skill development and reproduction, to the extent that a majority of the respondents had undertaken some form of training to re-skill so as to be employable in growing sectors of the economy. In addition, there was significant financial assistance provided by central and local government and also by the regional development body, Advantage West Midlands under the auspices of the MGR Task Force. While employment outcomes have varied across workers depending on their personal characteristics, it seems that the relative buoyancy and diversity of the local and regional economy at the time of the closure combined with a willingness on the part of some workers to 
increase their commuting time and to take advantage of training opportunities enabled most disadvantaged workers (in terms of age and experience) to find a job in the medium term.

Yet two-thirds of respondents had suffered a very significant fall in earnings relative to their job at MGR. A sudden influx of workers caused by the closure had placed further pressure on some already depressed local labour markets and generated further 'knock-on' competition for what (low-wage) jobs were available (Chapain and Murie, 2008). This overall fall concealed earnings polarisation, in that one third of respondents reported an increase in earnings relative to MGR. Having to cope with reduced earnings only increased the financial pressures on households, something which the recent credit crunch and prospect of further redundancies has only exacerbated.

\section{Discussion and policy implications}

Our findings suggest implications and lessons for urban policy. In particular, dealing with plant closure as part of a broader strategy for urban renewal needs to acknowledge the differential geographies of place. Here, 'place' may be defined not as "a bounded entity but must be seen rather as a jagged fragment drawn from systems that are larger, as well as a rough assemblage of many things that are smaller" (Collinge and Gibney, 2010: 382). By this we mean that a "place" may not be thought of as being coterminous with one Local Authority operating in isolation, but rather that localities are interconnected and affected by what happens in other localities, and the actions of sub-local, regional and national actors, and thus require coordinating mechanisms to highlight (and act on) shared interests - as demonstrated by the fact that ex-MGR workers and supplier firms were scattered across the West Midlands. This was evident in the Regional Development Agency's Task Force approach in bringing stakeholders together and providing a coordinated local response that individual groups may have struggled to achieve. As van Winden (2008: 198) argues:

"Cities are not passive 'receivers' of global trends: they can take action to make themselves 'fit' for the knowledge economy through initiatives of local leaders or coalitions. Concerted action in the form of cooperations between municipal authorities, companies, and local knowledge institutions in the city can be effective, if designed properly and realistically."

However, this requires the development of local and regional strategic capacities over the longer term. In addition, some form of planning for potential economic shocks is important to help mitigate them in advance or to be able to respond quickly. Another key policy lesson is the need for agencies to move swiftly; it is helpful to have knowledge and actions in place rather than 'fire fighting' after the event. When MGR closed in April 2005, the second Task Force was able to start work on the day of the closure announcement. Such advance preparation work could work well in future closure situations, as it is unlikely that a future closure would happen without at least some prior warning. There is therefore a need for a 'permanent capacity' to deal with these issues, as a way of having institutional memory of how things were done. It is interesting that when the Birmingham van maker LDV went into administration in June 2009, a task force was set up immediately, learning from the MGR experience, and staffed by some of the same people. The regional task forces put in place during the recession have also been modelled on the MGR experience, albeit in very different circumstances. There have been calls to make these permanent so as to retain this knowledge and capacity (House of Commons, 2009), although this now seems unlikely in the post-election context of the abolition of RDAs. Indeed, with the abolition of RDAs by the coalition government, it is not clear that fragmented local enterprise partnerships (LEPs) will be able to provide the coordinated leadership needed to effectively tackle such situations. 
The economic diversification of Birmingham and the West Midlands in the first half of 2000s also played an important role in enabling workers to adjust post MGR closure. As such, economic diversification should be further encouraged, particularly post credit crunch. As Clayton (2009) notes, the impact of the current downturn was felt differently across different regions of the UK, in turn requiring that labour market policies are built on local initiatives and local knowledge. On this note, government and regional development agencies (or successor bodies) need to do more to ensure that employees have the necessary skills to cope as industries change, through high quality, flexible education, training, information, and mobility programmes (a more 'Nordic' approach). Here it needs to be recognised that much work was done by the RDA Advantage West Midlands and other agencies before the MGR closure, in diversifying the supply chain and economy and this work may have 'saved' as many as 10-12,000 jobs in the local automotive supply chain at the time (Bailey and MacNeill, 2008). Avoiding sudden closures and slowing down the process where possible also enables workers released to pick up jobs arising through 'replacement demand' where firms require workers to cover those who have left, retired and so on. Such replacement demand can actually be quite significant and in the medium term may outweigh negative changes arising from projected decline (Wilson et al., 2006). These policy suggestions from MGR experience accord with a view of plant closures not as discreet one-off events but rather long-term path-dependent processes (Pike, 2005) beginning well before the 'event' itself and with repercussions continuing well after. At critical moments there may be significant opportunities for local and regional policy interventions which may alter evolutionary trajectories (Bailey et al, 2010).

Finally, the 'success' story noted earlier in respect of retraining in the case of ex-MGR workers seems linked to the specific forms of training and education that were taken up and which provided skills of use in the local labour market. Training and education played a key role in particular in ensuring those who did not find re-employment quickly were not left unsupported.

\section{Conclusion}

This paper has presented a longitudinal analysis of the labour market adjustment of workers made redundant following a plant closure in a post-industrial city by looking at the example of the closure of MG Rover in 2005 in Birmingham, UK. More specifically, the paper examines to what extent the state of the local and regional labour markets and workers' geographical mobility - as well as the effectiveness of the immediate policy response and longer term local economic strategies - may have helped balance the impacts of personal attributes associated with workers' employability and re-absorption into the labour markets. As such, our findings suggest that the then relative buoyancy of the local and regional economy, supported by economic diversification strategies, as well as a strong policy response and retraining initiative did indeed play a role in enabling the most disadvantaged workers to find a new jobs in the medium term. While younger and highly skilled workers were usually able to find another job quickly and more often in the manufacturing sector, older and less skilled and experienced workers took longer to find new jobs but were able to do so in the growing local and regional service sectors and usually by experiencing some form of retraining. These positive impacts are illustrated by the fact that approximately $90 \%$ of ex-MGR workers had obtained some form of employment by April 2008, with nearly three-quarters employed full-time. In contrast, only 5\% were still unemployed and looking for work. However, our findings also highlight sharp declines in income for many, with a majority of respondents reporting a considerable decline in real earnings compared to when they worked at MGR; and further that a quarter of respondents reported that they were experiencing financial difficulties. The findings also indicated polarisation through a greater dispersion of earnings. Our analysis confirms the unequal employment outcomes and trajectories that many lesser-skilled workers leaving traditional 
industries can encounter and the critical role played by short and long term policies to help them in this process.

In terms of policy responses, much work was done by the RDA Advantage West Midlands and other agencies before the MGR closure in diversifying the supply chain and economy and this avoided much larger job losses in the supply chain. These specific measures were reinforced by wider local and regional economic development strategies implemented at the beginning of 2000s. In addition, when MGR closed in 2005, the MGR Task Force II was able to start work immediately on the day of the announcement of the closure. Such advance preparation undeniably helped cushion some of the impacts of the closure and could be used in future closure situations, as it is unlikely that a future closure would happen without at least some prior warning. This lesson points towards the need for good 'institutional memory' of how to operate in such situations, with some sort of permanent capacity to deal with closures, in addition to efforts to promote economic diversification and consequent urban renewal. In this regard, as has been noted in other studies of plant closures, the strength of the local economy and labour market is a key determinant of how many workers will find re-employment. With the abolition of regional development agencies by the coalition government, a key task for Local Enterprise Partnerships will be to capture the existing regional 'institutional memory'.

\section{References:}

Armstrong, H. and Taylor, J. (1993) 'Regional Economics and Policy' 2nd edition, Philip Allan: Oxford.

Bailey, D., 2003. 'Globalisation, regions and cluster policies: the case of the MG Rover Task Force.' Policy Studies, 24 (2/3), 67-85.

Bailey, D., Chapain, C., Fauth B. and Mahdon M. 2008 Life after Longbridge: Three Years on. Pathways to Re-employment in a Restructuring Economy. London: The Work Foundation.

Bailey, D. and MacNeill, S. (2008) 'The Rover Task Force: A Case Study in Proactive and Reactive Policy Intervention?' Regional Science Policy and Practice. 1(1), 1-16.

Bailey, D., Bellandi, M., Caloffi, A. and De Propris, L. (2010) 'Place-renewing leadership: trajectories of change for mature manufacturing regions in Europe,', Policy Studies, 31(4), 457474

Bailey, N. and Turok, I. (2000) 'Adjustment to Job Loss in Britain's Cities', draft paper: University of Glasgow.

Birmingham City Council (2009) Birmingham Ward Unemployment Time Series. Economic Information and Strategy, Birmingham: Birmingham City Council.

Brown J., Chapain, C., Murie, A. Barber, A., Gibney, J. and Lutz, J. (2007), From a city of a thousand trades to a city of a thousand ideas. ACRE report 2.3. Accommodating Creative Knowledge - Competitiveness of European Metropolitan Regions within the Enlarged Union. AMIDSt, University of Amsterdam, Amsterdam.

Chapain, C. and Murie, A. (2008) 'The impact of factory closure on local communities and economies: the case of the MG Rover Longbridge closure in Birmingham.' Policy Studies, 29 (3), 305-317

Clayton, N. (2009) 'The Geography of Unemployment: How the recession has affected different cities', London: The Work Foundation. 
Collinge, C. and Gibney, J. (2010) ‘Connecting place, policy and leadership', Policy Studies, 31 (4): 379-91.

Dawley, S. (2007) 'Making labour-market geographies: volatile 'flagship' inward investment and peripheral regions', Environment and Planning A, 39: 1403-19.

Dorling, D. (2009) 'Unemployment and health. Health benefits vary according to the method of reducing unemployment', $B M J, 338:$ b829

Fothergill, S. (2009) The Impact of Recession on Unemployment in Industrial Britain. Barnsley: Industrial Communities Alliance.

Glasmeier, A., Martin, R., Tyler, P. and Dorling, D. (2008) 'Editorial: Poverty and place in the UK and the USA', Cambridge Journal of Regions, Economy and Society, 1 (1): 1-16.

Gospodini, A. (2009) 'Post-industrial Trajectories of Mediterranean European Cities: The Case of Post-Olympics Athens', Urban Studies, 46 (5\&6): 1157-86.

Harris, C. (1987) 'Redundancy and Recession in South Wales'. Oxford: Blackwell.

Henderson, R. and Shutt, J. (2004) 'Responding to a coalfield closure: old issues for a new regional development agency?', Local Economy, 19 (1), 25-37.

Hinde, K. (1994) 'Labour market experiences following plant closures: The case of Sunderland's shipyard workers', Regional Studies, 28: 713-24

House of Commons (2009), Select Committee on the West Midlands. The Impact of the Current Economic and Financial Situation on Businesses in the West Midlands Region. London: The Stationery Office. HC 409-I/HC409-II.

Hudson R. (2010) 'The changing geography of manufacturing and work: made in the UK?' in In Coe N. and Jones A. The Economic Geographies of the UK. London: Sage.

Kirkham, J. and Watts, H., (1998) 'Multi-locational manufacturing organisations and plant closures in urban areas.' Urban Studies, 35 (9), 1559-1575.

MacKinnon, D., Cumbers, A. and Shaw, J, (2008) 'Rescaling employment relations: key outcomes of change in the privatised rail industry', Environment and Planning A, 40: 1347-69.

Mommaas, H. (2004) 'Cultural Clusters and the Post-industrial City: Towards the Remapping of Urban Cultural Policy', Urban Studies, 41 (3): 507-532.

Nolan, P. (2004) 'Editorial: Shaping the future: the political economy of work and employment', Industrial Relations Journal, 35(5): 378-87.

O'Farrell, N. and Crouchley, P. (1983) 'Industrial closures in Ireland 1973-1981: Analysis and implications', Regional Studies, 17: 411-28

Pike, A. (2005) 'Building a Geographical Political Economy of Closure: The Case of R\&DCo in North East England', Antipode: 37(1): 93-115.

Pinch S. and Mason C. (1991), "Redundancy in an Expanding Labour Market: a Case-study of Displaced Workers from Two Manufacturing Plants in Southampton." Urban Studies, 28 (5): 735-757.

Shuttleworth, I., Tyler, P. and McKinstry, D. (2005) Redundancy, readjustment, and employability: what can we learn from the 2000 Harland \& Wolff redundancy? Environment and Planning A., 37: 1651-1668

Tomaney J., Pike, A. and Cornford, J. (1999) 'Plant closure and the local economy: The case of Swan Hunter on Tyneside', Regional Studies, 33 (5): 401-11. 
van Winden, W. (2008) 'Urban governance in the knowledge-based economy: Challenges for different city types', Innovation: management, policy \& practice, 10: 197-210.

Waring, P., De Ruyter, A. and Burgess, J. (2006) 'The Australian Fair Pay Commission: Rationale, Operation, Antecedents and Implications', Economic and Labour Relations Review, 16 (2): 127-46.

Wilson, R., Homenidan, K. \& Dickinson, A. (2006) 'Working Futures 2004-2014 National Report', Wath-Upon-Dearne; Sector Skills Development Agency, 2006.

Wooden M. (1988) 'The Impact of Redundancy on Subsequent Labour Market Experience.' Journal of Industrial Relations, 30 (3): 3-31. 